\title{
Avaliação de dois modelos experimentais de isquemia e reperfusão cerebral em ratos com oclusão temporária carotídea associada ou não à oclusão vertebral ${ }^{1}$
}

\author{
Daniela Mazza Sundefeld Tardini² \\ Winston Bonetti Yoshida ${ }^{3}$ \\ Ethel Lourenzi Barbosa Novelli ${ }^{4}$ \\ Júlio Lopes Sequeira ${ }^{5}$
}

\begin{abstract}
Tardini DMS, Yoshida WB, Novelli ELB, Sequeira JL. Avaliação de dois modelos experimentais de isquemia e reperfusão cerebral em ratos com oclusão temporária carotídea associada ou não à oclusão vertebral. Acta Cir Bras [serial online] 2003 Nov-Dez;18(6). Disponível em URL: http://www.scielo.br/acb.

RESUMO - Objetivo: Avaliar a reprodutibilidade de dois modelos experimentais de isquemia e reperfusão cerebral. Métodos: 60 ratos foram distribuídos, aleatoriamente, em três grupos experimentais, com 20 animais cada: I- pinçamento temporário de artéria carótida esquerda; II - cauterização prévia das artérias vertebrais e pinçamento temporário da artéria carótida esquerda; simulado - sem isquemia nem reperfusão. Todos os animais tiveram oclusão definitiva de artéria carótida direita e os três grupos foram subdivididos em dois períodos de reperfusão: A - 60 minutos e B - 120 minutos. Os parâmetros verificados foram: medidas de pressão arterial média sistêmica e fluxo sangüíneo carotídeo; medida de malondialdeído cerebral através do teste TBARS e avaliação histológica do hemisfério cerebral submetido à isquemia e reperfusão. Foi feito também um estudo complementar com angiografia cerebral em 5 animais adicionais. Resultados: Não houve diferenças significativas nas dosagens de malondialdeído cerebral e na frequiência e gravidade das alterações histológicas cerebrais entre os três grupos. Nos grupos GI e GII, a PAM foi significantemente maior no período de isquemia. O fluxo sangüíneo entre os períodos pré e pós-pinçamento aumentou nos grupos IA e IIB, diminuiu no grupo IB e no grupo IIA manteve-se inalterado. As angiografias do estudo complementar mostraram aporte sangüíneo para cérebro através de circulação colateral. Conclusão: Os modelos de isquemia e reperfusão estudados não demonstraram alterações consistentes de marcadores de lesão cerebral, seja quanto à produção de lipoperóxidos ou de lesões histológicas.
\end{abstract}

DESCRITORES - Isquemia e reperfusão cerebral. Lipoperoxidação.

\section{Introdução}

A doença aterosclerótica das artérias carótidas pode provocar sintomas como amaurose fugaz, cefaléia ou acidente isquêmico transitório (AIT). O quadro clínico mais temido é o acidente vascular cerebral (AVC), não apenas pelas seqüelas incapacitantes que podem ocorrer, mas principalmente, pelo risco de óbito; sabese que, nos Estados Unidos, o AVC é a terceira causa mais freqüente de morte. Deve-se ressaltar que, no primeiro ano após a ocorrência de um episódio de AIT, há um risco de, aproximadamente, $10 \%$ de o paciente vir a apresentar AVC. Também é importante ressaltar que, os pacientes assintomáticos e portadores de estenose carotídea maior ou igual a $75 \%$ têm um risco de 3 a $5 \%$ de virem a apresentar AVC, por ano de seguimento ${ }^{1,2}$.

Estudos prospectivos importantes como o NASCET ${ }^{3}$ e European Carotid Trial (4), que focalizaram pacientes sintomáticos, e o $\operatorname{ACAS}^{5,6,7}$ e Veterans Affairs Cooperative Study Group ${ }^{8}$, que seleciona- ram pacientes assintomáticos, demonstraram que os pacientes submetidos à cirurgia de endarterectomia de carótida apresentaram redução significativa das taxas de ocorrência de AVC em relação aos pacientes tratados clinicamente.

Entretanto, na cirurgia de endarterectomia de carótida, independentemente da técnica cirúrgica empregada, há necessidade de se promover a oclusão temporária da artéria a ser operada, o que pode, eventualmente, desencadear lesões decorrentes de isquemia cerebral de intensidade

1. Trabalho desenvolvido na Disciplina de Cirurgia Vascular do Departamento de Cirurgia e Ortopedia da Faculdade de Medicina de Botucatu - UNESP, Botucatu -SP-Brasil.

2. Mestre em Cirurgia pela Faculdade de Medicina de Botucatu - UNESP. Residência Médica em Angiologia e Cirurgia Vascular.

3. Professor Adjunto Livre-docente da Disciplina de Cirurgia Vascular do Departamento de Cirurgia e Ortopedia da Faculdade Medicina de Botucatu - UNESP

4. Professora Doutora Titular do Departamento de Química e Bioquímica do Instituto de Biociências de Botucatu - UNESP.

5. Professor Doutor Assistente do Departamento de Clínica Veterinária da Faculdade de Medicina Veterinária e Zootecnia de Botucatu - UNESP. 
variável, seguida de reperfusão. Como manifestação clínica, poderá haver a presença de edema cerebral, caracterizando a síndrome de hiperperfusão pósoperatória, a qual, ocorre mais frequientemente em pacientes hipertensos crônicos e /ou portadores de estenoses carotídeas maiores que $90 \%$.

Durante a fase de isquemia, ocorre diminuição do aporte de oxigênio para o tecido cerebral, levando a inibição de fosforilação oxidativa mitocondrial e a queda da produção energética celular. Uma das conseqüências dessa isquemia é a degradação dos fosfolípides da membrana celular, por ação das fosfolipases A e C, liberando grande quantidade de ácidos graxos livres (AGL). Na fase da reperfusão, os AGL acumulados no tecido cerebral, durante a isquemia, sofrem metabolização pelas vias da lipoxigenase e cicloxigenase, formando tromboxanos, prostaglandinas e superóxidos, sendo estes últimos radicais livres ${ }^{11,12,13,14}$. Uma importante conseqüência da formação de radicais livres é a peroxidação lipídica, a qual, se propaga na forma de uma reação em cadeia autocatalítica. Os ácidos graxos livres insaturados são bastante suscetíveis a esse processo de lipoperoxidação ${ }^{15,12,16}$.

Na isquemia, também há maior entrada de $\mathrm{Ca}^{++}$para o citossol, promovendo a quebra de uma ponte peptídica da enzima xantina desidrogenase (XD) e levando à formação da enzima xantina oxidase (XO). Com a reperfusão, a xantina oxidase (XO) leva a formação de xantina e promove sua oxidação em ácido úrico, tendo como subproduto dessa reação a formação do ânion superóxido, um radical livre ${ }^{17}$. Ainda relacionado ao aumento de $\mathrm{Ca}^{++}$no citossol, há aumento da liberação de glutamato, um neurotransmissor excitatório que estaria aumentado no meio extracelular. Esse gradiente aumentado de glutamato extracelular na isquemia também seria um "precursor", ou seja, fonte de radicais livres, para as alterações que viriam a ocorrer durante a reperfusão $0^{13 ; 18 ; 19}$. Da mesma forma, ocorre formação de óxido nítrico (NO) a partir da L-arginina ${ }^{20 ; 21 ; 22}$ pela ação da óxido nítrico sintase constitutiva (cNOS), $\mathrm{Ca}^{++}$dependente.

O tecido cerebral é, particularmente, susceptível às lesões por agentes oxidantes, pois possui grandes reservas de ferro e altos níveis de lipídios polinsaturados e porque possui uma pobre defesa antioxidante ${ }^{23}$. Alguns autores observaram em estudos realizados em pacientes submetidos a endarterectomia de carótida ${ }^{24,25,23}$ que houve tanto presença de lipoperoxidação, quanto a diminuição de antioxidantes plasmáticos e concluíram que, esses resultados, poderiam ser indicativos da presença de produção de radicais livres no tecido cerebral durante a cirurgia de endarterectomia de carótida.

Os estudos experimentais são necessários não apenas para a confirmação e esclarecimento dos dados encontrados nos estudos clínicos, mas também para se encontrar os tratamentos que atenuem essas lesões. Os modelos experimentais de isquemia e reperfusão cerebral, no entanto, são variáveis e nem sempre reprodutíveis.

Em vista disso, o objetivo deste trabalho foi analisar dois modelos de isquemia e reperfusão cerebral. Para tanto, foram avaliados: a lipoperoxidação cerebral, o fluxo sangüíneo de artéria carótida esquerda, a pressão arterial média e as alterações histológicas cerebrais. Foi também realizado um estudo angiográfico cerebral complementar com o objetivo de verificar a oclusão das artérias vertebrais.

\section{Métodos}

Foram utilizados 60 ratos machos da raça Wistar, com idades entre 60 e 65 dias e com pesos entre $200 \mathrm{~g}$ e $300 \mathrm{~g}$, fornecidos pelo Biotério Central do Campus de Botucatu - UNESP, tendo sido o delineamento experimental aprovado pela Comis=são de Ética na Experimentação Animal da Faculdade de Medicina de Botucatu UNESP (Protocolo número: 150, 24/06/ 2002).Todos os animais foram submetidos a dissecção das artérias vertebrais e, após esse procedimento, foram aleatoriamente divididos em três grupos experimentais com vinte animais em cada um.

- GRUPO I - simulação da cauterização das artérias vertebrais e oclusão temporária, por 30 minutos, da artéria carótida comum esquerda.

- GRUPO II - cauterização das duas artérias vertebrais, seguida de um período de 24 horas de repouso. Após esse período, foi realizada oclusão temporária, por 30 minutos, da artéria carótida comum esquerda.
- SIMULADO (III) - simulação tanto da cauterização das artérias vertebrais, quanto da oclusão da artéria carótida comum esquerda.

Os animais de cada grupo foram, posteriormente, subdivididos em dois subgrupos, com dez animais cada um, de acordo com tempo de reperfusão: Subgrupo A: 60 minutos de reperfusão e Subgrupo B: 120 minutos de reperfusão. Após jejum por 12 horas os animais foram anestesiados com pentobarbital na dose de $30 \mathrm{mg} / \mathrm{Kg}$, por via intraperitoneal. Em todos os animais, realizou-se tricotomia e anti-sepsia da face anterior do pescoço e da região cervical posterior e, em seguida, foi feita incisão em linha mediana cervical posterior, próxima à base do osso occipital, com dissecção de musculatura paravertebral e localização do corpo vertebral de $\mathrm{C} 1$ e de seus forames laterais, por onde foram visualizadas as artérias vertebrais. Após a dissecção das artérias vertebrais, apenas nos animais do Grupo II, foi feita a cauterização dessas artérias (Eletrocautério bipolar Imbracrios, modelo BE 200). Depois desse procedimento, estes ratos (GII) permaneceram 24 horas em repouso e foram, então, novamente anestesiados, dando seqüência às demais etapas experimentais. Nos animais dos grupos I e III a dissecção vertebral foi feita imediatamente antes da dissecção carotídea, sem o intervalo de 24 horas, entre esses procedimentos. Em todos os animais foi realizada incisão mediana na região cervical anterior e dissecção das artérias carótidas. Foi feito o cateterismo proximal da artéria carótida comum direita para medida contínua de pressão arterial média (Fisiógrafo BIOPAC, modelo MP-100). Somente nos grupos GI e GII foi aplicado, externamente na artéria carótida comum esquerda, um transdutor para medida de fluxo sangüíneo (Fluxômetro ultrassônico Transonic System Inc, modelo HT-207). O fluxo sangüíneo carotídeo foi registrado durante 10 minutos aos: 10 minutos após o início do procedimento, 10 minutos após o início da isquemia e 10 minutos após o início da reperfusão. O fluxo sangüíneo não foi registrado no grupo III, pois nesses animais não houve o período de pinçamento. A temperatura esofágica foi medida previamente ao período de isquemia e foi, novamente, verificada durante os períodos de isquemia e de reperfusão 
(Fisiógrafo BIOPAC, modelo MP-100). A temperatura não foi medida continuamente, mas durante aproximadamente 5 minutos em cada uma das fases experimentais, em todos os animais. Em todos os animais, procurou-se manter a temperatura corporal entre 33 e 34 graus Celsius, com auxílio de calor de lâmpada externa e do uso de compressas grandes aquecidas durante todo o experimento. Após intervalo de 20 minutos para estabilização hemodinâmica do animal, realizou-se o pinçamento temporário da artéria carótida comum esquerda por 30 minutos nos grupos GI e GII, e simulação no grupo III, com reperfusão por 60 ou $120 \mathrm{~min}$, conforme os subgrupos descritos. Ao final do período de reperfusão, os animais foram sacrificados por excesso anestésico. Realizou-se, então, craniectomia e ressecção do hemisfério cerebral esquerdo para estudos bioquímicos e para análise histológica. A metade anterior do hemisfério cerebral esquerdo $(200 \mu \mathrm{g})$ foi pesada, identificada e resfriada em nitrogênio líquido para posterior dosagem de malondialdeído pelo método do ácido tiobarbitúrico, padronizado por Slater ${ }^{26}$. Os fragmentos foram homogeneizados (Homogeneizador Virtis Company, modelo Virtis 23, teflon) em $2 \mathrm{~mL}$ de tampão fosfato, $\mathrm{pH} 7,0$ e, posteriormente, centrifugados por5 minutos a 1000rpm (Centrífuga Fanem, modelo 215). Colheu-se $200 \mu \mathrm{L}$ do sobrenadante do homogenato centrifugado e a ele foram adicionados: $1 \mathrm{~mL}$ de ácido tricloroacético $20 \%$ e $400 \mu \mathrm{L}$ de ácido tiobarbitúrico a $1,6 \%$, sendo essa mistura incubada por 30 minutos a 95 graus Celsius.Os lípides foram extraídos através da mistura com n-butanol (1,6 mL), de vigorosa agitação e nova centrifugação por 10 minutos a 3000rpm. A absorbância de camada orgânica foi medida em espectrofotômetro (530nm) (Espectofotômetro Pharmacia Biotech Ultrospec 3000, UV/Visible Spectophotometer). Os níveis de malondialdeído foram expressos em valores de absorbância e em nanomoles de malondialdeído por grama de tecido.

Para análise histológica, um fragmento de tecido cerebral, com 1 a $2 \mathrm{~mm}$ de espessura obtido no sentido coronal da região média do hemisfério esquerdo, foi fixado em formol a $10 \%$, incluído em parafina, cortado e corado pelo método da Hematoxilina-Eosina para avaliação histo- lógica. A avaliação foi feita por patologista sem conhecimento prévio dos grupos, tendo sido realizada apenas análise qualitativa das lâminas, visando-se verificar a presença de alterações como: edema cerebral, citoplasma eosinofílico ou infarto cerebral.

Os dados de medidas de dosagem de malondialdeído foram submetidos à análise estatística através da Análise de Variância ao nível de 5\%. Às medidas de fluxometria foi aplicada Análise de Variância com medidas repetidas no tempo e realizada a decomposição da interação grupo versus tempo, ao nível de 5\%. As medidas de pressão arterial média foram analisadas utilizando-se a Análise de Variância de um esquema multifatorial e foi feita a decomposição da interação grupo versus tempo, ao nível de 5\%.

Em cinco animais adicionais, com mesmo porte e idade dos animais utilizados no experimento principal, foi feito um estudo angiográfico cerebral em aparelho com subtração digital (Philips, modelo BV300), utilizando-se como meio de contraste a Massa de Schlesinger ${ }^{27}$. Sob anestesia com pentobarbital sódico $(30 \mathrm{mg} / \mathrm{Kg}$, por via intraperitoneal), foi feita a cauterização das duas artérias vertebrais, como descrito anteriormente e, 24 horas após, novamente sob anestesia, realizou-se a ligadura de ambas artérias carótidas comuns, seguida de toracotomia para dissecção da aorta torácica e de veias cavas superior e inferior. $\mathrm{Na}$ aorta torácica realizou-se ligadura distal e cateterismo proximal com cateter de polietileno. As veias cavas foram seccionadas parcialmente. Foi feita perfusão cerebral com solução salina $0,9 \%$ gota a gota, através do cateter na aorta torácica, até que, houvesse saída apenas da solução salina pelas veias cava superior e inferior. Nesse momento, iniciou-se a infusão do meio de contraste (massa de Schlesinger), pelo mesmo cateter, com pressão de 120 a $140 \mathrm{mmHg}$, até ocorrer escoamento desse meio através das secções venosas. As imagens angiográficas com subtração digital foram registradas durante toda a fase de preenchimento do leito vascular com a massa.

\section{Resultados}

Os animais apresentaram médias de idade de 62 dias (mínima de 60 e máxima de 64 dias) e de peso de 254,4g (mínimo de 215 e máximo de $300 \mathrm{~g}$ ).

Não houve diferença, estatisticamente significativa, entre as determinações de malondialdeído (MDA) nos grupos estudados (Figura 1).

Houve aumento, estatisticamente significativo, do fluxo sangüíneo entre os períodos pré e pós-isquemia nos grupos GIA e GIIB e foi observada diminuição significativa no grupo GIB. Não foi encontrada alteração entre os períodos pré e póspinçamento no grupo GIIA (Figura 2).

Verificou-se que a Pressão Arterial Média no subgrupo III A foi 123,8 $\pm 3,8$ $\mathrm{mmHg}$ e no subgrupo III B, 126,7 $\pm 2,6$ mmHg.Nos outros grupos houve aumento significativo da PAM durante a fase de pinçamento de artéria carótida comum esquerda, com retorno aos níveis iniciais após a reperfusão (Figura 3).

Foi realizada somente avaliação histológica descritiva do tecido cerebral. As alterações histopatológicas cerebrais foram discretas e não apresentaram diferenças de freqüência e intensidade entre os grupos experimentais estudados. O edema da substância branca cerebral foi mais comumente observado no córtex da região dos lobos temporais e parietais e no hipocampo. Eventualmente, os vasos das meninges da região parieto-temporal, mostraram discreta congestão. No Grupo IB, o edema do tecido nervoso cerebral tendeu a ser um pouco mais intenso que nos demais grupos. Neurônios contraídos, com citoplasma acidofílico e eventualmente vacuolizados, além da presença de espaço perineuronal foram observados, de forma esparsa, no córtex da região dos lobos temporais e parietais e em áreas focais do hipocampo, em todos os grupos. Alterações isquêmicas mais graves como infartos ou áreas de malácia não foram observados em nenhum dos grupos. (Tabela 1)

No Experimento Complementar, verificou-se que todos os 5 animais estudados apresentaram preenchimento vascular cerebral através de circulação colateral, cuja origem não foi possível identificar. Em um dos animais observouse que uma das artérias vertebrais permaneceu pérvia, apesar de ter sido submetida aos mesmos procedimentos que os demais (Figuras 4 e 5). 


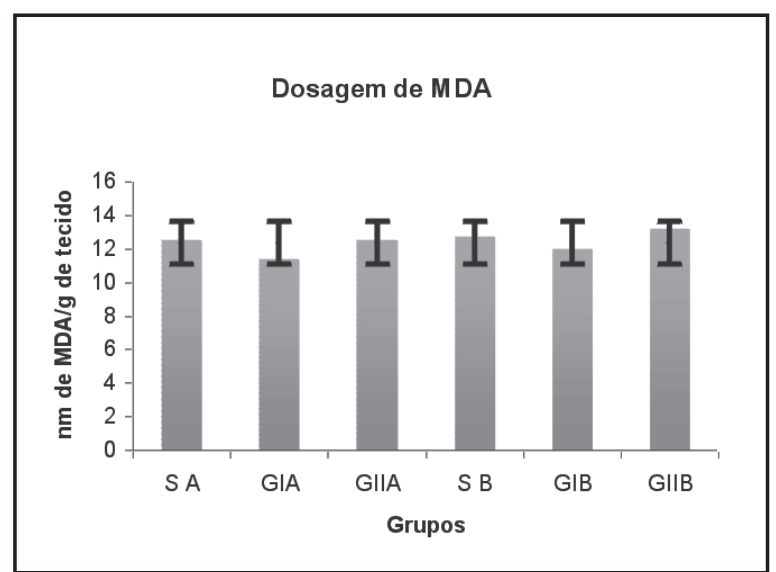

FIGURA 1 - Médias e desvios-padrão das medidas de MDA nos três grupos e seus respectivos subgrupos.

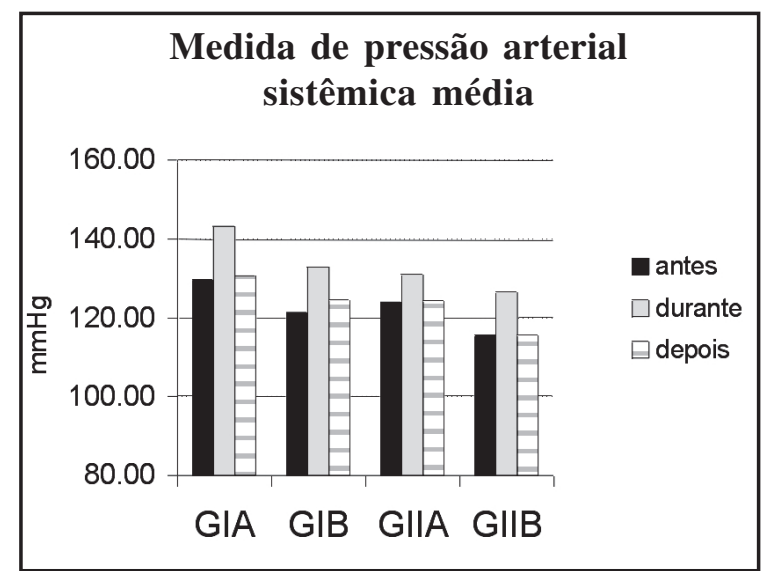

FIGURA 3 - Valores médios de PAM (em $\mathrm{mmHg}$ ) antes, durante e depois da oclusão temporária da artéria carótida esquerda, nos grupos estudados.

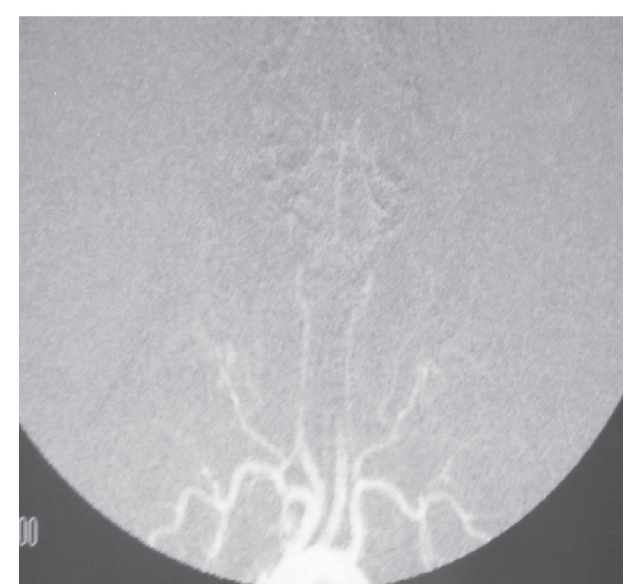

FIGURA 4 - Angiografia digital mostrando ambas artérias vertebrais cauterizadas e existências de enchimento de leito vascular cerebral.

\section{Discussão}

Diversos modelos experimentais foram desenvolvidos para se estudar melhor a fisiopatologia e o potencial tera-

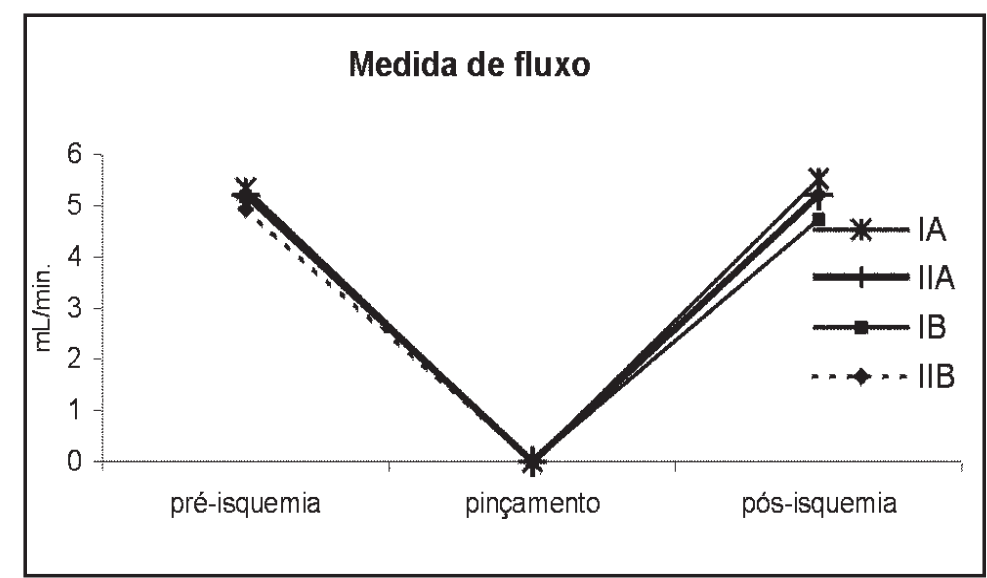

FIGURA 2 - Médias de velocidade de fluxo da artéria carótida esquerda, antes da oclusão temporária, durante e após a reperfusão, nos Grupos I e II. Valores em mililitros por minuto.

TABELA 1 - Presença e intensidade das alterações histológicas verificadas no tecido cerebral ao final do experimento, em todos os grupos experimentais.

\begin{tabular}{c|cccccc}
\hline & GIA & GIIA & GIB & GIIB & S A & S B \\
\hline Edema & + & + & + & + & + & + \\
Neurônios contraídos & + & + & + & + & + & + \\
$\begin{array}{c}\text { Neurônios vacuolizados } \\
\text { Infarto }\end{array}$ & + & + & + & + & + & + \\
& - & - & - & - & - & - \\
\hline
\end{tabular}

+ grau discreto; ++ grau moderado; - ausente (avaliação descritiva das lâminas) 
modelos encontrados na literatura, associando-se ou não a oclusão das artérias vertebrais.

No modelo de isquemia do Grupo I não foi feita a cauterização de artérias vertebrais (2VO), ou seja, apenas realizouse o pinçamento das artérias carótidas. A ausência de diferenças significativas de alguns dos parâmetros estudados, entre os animais submetidos à isquemia e aqueles do grupo simulado nesse estudo, poderia ser creditada à circulação colateral mais proeminente nesses animais. Sabese que os ratos apresentam o Polígono de Willis bem desenvolvido, por esse motivo, quando submetidos à isquemia $2 \mathrm{VO}$, isoladamente, há diminuição do aporte sangüíneo cerebral em somente cerca de $50 \%{ }^{(13,28)}$. Essa isquemia tenderia a ficar mais intensa se associada a diminuição da pressão arterial média do animal, durante o pinçamento da artéria carótida ${ }^{13}$. Já, animais como as cobaias, possuem o Polígono de Willis incompleto ${ }^{13}$ e por esse motivo, em geral, não necessitam ser submetidos à hipotensão ou a outros artifícios adicionais para se promover isquemia e reperfusão cerebral.

Para diminuir a influência da circulação colateral nos modelos de isquemia e reperfusão, Pulsinelli e col..$^{29}$ descreveram, em 1979, a associação da cauterização das artérias vertebrais ao modelo de $2 \mathrm{VO}$. Essa técnica foi capaz de promover, segundo alguns autores, diminuição de 90 a $95 \%$ do aporte sangüíneo para os hemisférios cerebrais do rato, quando associada à isquemia temporária de ambas carótidas ${ }^{13}$ ${ }^{28}$. O Grupo II do presente estudo reproduziu esse modelo (4VO), com a diferença de que se realizou isquemia temporária apenas da artéria carótida esquerda, uma vez que a outra artéria carótida encontrava-se permanentemente ocluída pela ligadura e cateterismo. Como não houve diferenças significativas nas dosagens de MDA e na análise histológica, em comparação com os grupos "sham" , o aporte sangüíneo cerebral nesses animais chegou, possivelmente, através de circulação colateral. O estudo complementar mostrou que essa circulação colateral poderia estar realmente presente, pois houve preenchimento de leito vascular cerebral nos cinco animais estudados e submetidos aos mesmos procedimentos do grupo II. Esse fluxo colateral, ainda que reduzido, poderia ser capaz de evitar a peroxidação lipídica e lesões decorrentes de isquemia e reperfusão cerebrais, avaliados pela dosagem do MDA cerebral e estudo histológico.

Em estudo recente, Islekel e col, ${ }^{30}$ submeteram ratos à técnica $4 \mathrm{VO}$ e à isquemia incompleta, com períodos de reperfusão variáveis $(0,20,60$ e 240 minutos). Verificaram que, quando esses animais eram comparados com o grupo "sham" não havia diferenças nas dosagens do MDA cerebral. No entanto, neste mesmo experimento, ao associarem o uso de um torniquete insuflado ao redor do pescoço dos animais, verificaram diferença significativa da dosagem de MDA cerebral entre os animais submetidos a isquemia e reperfusão e os simulados. Os autores concluíram que a circulação colateral advinda de ramos cervicais das artérias subclávias poderia ser suficiente para a prevenção da lipoperoxidação cerebral ${ }^{30}$.

Com relação ao delineamento dos grupos do presente trabalho, a rigor deveria ter sido feito de uma forma um pouco diferente, ou seja, os animais dos grupos I e III deveriam ter sido submetidos a dissecção vertebral também 24 horas antes do início do experimento definitivo, de modo que houvesse homogeneidade dos tempos experimentais. Entretanto, acreditamos que este fator não deva ter pesado nos resultados encontrados, uma vez que nesses grupos as artérias vertebrais não foram cauterizadas.

O estudo angiográfico complementar, realizado no presente experimento, mostrou a presença de fluxo sangüíneo cerebral através de circulação colateral; no entanto, as imagens obtidas não permitiram definir o local de origem desse fluxo colateral. Em um dos animais, verificou-se ainda que uma das artérias vertebrais havia permanecido pérvia, apesar do mesmo rigor técnico usado nos demais animais, fato esse que poderia comprometer a reprodutibilidade desse modelo.

Quanto à avaliação da lipoperoxidação, no estudo atual, foi realizado o teste das substâncias reativas do ácido tiobarbitúrico (TBARS). Resultados semelhantes aos nossos foram encontrados no estudo realizado por Yoshida e col..$^{31}$, que provocaram isquemia e reperfusão cerebral em cobaias mediante pinçamento temporário de ambas as artérias carótidas (2VO). Neste estudo os autores também não encontraram diferenças no teste das substâncias reativas do ácido tiobarbitúrico (TBARS) entre o grupo "sham" e os grupos que foram submetidos a 2VO. Em outro estudo, MacMillan também não verificou diferença nas dosagens de MDA em ratos submetidos à cauterização das artérias vertebrais e pinçamento temporário das artérias carótidas $(4 \mathrm{VO})^{32}$. Da mesma forma, Islekel e col. ${ }^{30}$ ao realizarem isquemia 4VO incompleta, como em nosso experimento, não observaram diferenças na dosagem de MDA entre os grupos simulados e os com isquemia e reperfusão, creditando esse resultado à possível presença de circulação colateral advinda das artérias subclávias ${ }^{30}$.

Em estudo realizado em ratos Wistar submetidos à técnica de $4 \mathrm{VO}$, não houve aumento de MDA em períodos de uma ou duas horas de reperfusão, mas quando foi prolongado esse período para além de oito horas verificou-se aumento significativo da dosagem de MDA, principalmente, nas regiões do córtex parietal e do neocórtex ${ }^{33}$. Por outro lado, os resultados de outros autores $^{13,16}$, revelaram aumento dos lipoperóxidos cerebrais, após curtos períodos de reperfusão. Muitos outros estudos mostraram também alterações significativas do MDA em fases precoces de reperfusão: Vagnozzi e col. (1994 e 1995), Seifel-Nars e El-Fattah (1995) e Siragusa e col. (1997) verificaram haver aumento significativo de MDA em ratos submetidos à isquemia e reperfusão cerebral, quando comparados aos grupos controle sem isquemia e reperfusão ${ }^{34,35,36,37}$. Foi com base nos resultados desses estudos que, no presente experimento, optou-se pelas dosagens de MDA nas fases mais precoces da reperfusão (uma e duas horas).

O método de dosagem das substâncias reativas do ácido tiobarbitúrico, embora simples, pode algumas vezes ser realmente pouco específico, levando a resultados díspares, ainda que sejam utilizadas metodologias criteriosas ${ }^{12,13,16}$. Uma das formas de se evitar variabilidade é através do controle do ambiente em que se realiza o experimento, do modo de armazenamento das amostras e do animal utilizado $^{13,38}$. Além disso, o teste TBARS, realizado por espectofotometria ou por fluorometria, identifica um produto (cromóforo) resultante da reação de duas moléculas de TBA com uma de MDA, mas, pode também reagir com outras substân- 
cias como a desoxirribose, as prostaglandinas e outros aldeídos, que não o MDA $^{12,16}$. Já, quando o teste é realizado por HPLC ("high-performance liquid chromatography"), os resultados são mais específicos, uma vez que somente o complexo TBA-MDA é determinado ${ }^{12,39}$.

Deve-se também ressaltar que as técnicas de dosagem do TBARS sofreram inúmeras modificações, algumas inapropriadas, e essas variações na metodologia de sua realização, acabaram interferindo na reprodutibilidade do teste ${ }^{12,16,38,39}$, tornando difícil a comparação da quantificação do teste TBARS entre os diversos estudos ${ }^{16}$

No presente estudo, é possível que o aporte sangüíneo cerebral através de circulação colateral e/ou por falha na cauterização das artérias vertebrais possa ter influenciado nos resultados atenuando a isquemia e as lesões de reperfusão.

Outro parâmetro avaliado em nosso estudo foi a medida de fluxo sangüíneo de artéria carótida comum esquerda, antes e após o seu pinçamento, usado, principalmente, para confirmação de oclusão do aporte sangüíneo para face e cérebro através da carótida esquerda. Os resultados de reperfusão observados não foram consistentes, o que impede uma análise mais criteriosa da possibilidade de hiperperfusão pós-isquemia. Da mesma forma que para as análises de outros parâmetros, este aspecto, em particular, do fluxo sangüíneo pós-reperfusão pode ter sido influenciado pelo suprimento colateral cerebral durante a isquemia. Meadow e colaboradores ressaltaram que a fluxometria, ultrassônica ou eletromagnética, confirmariam a interrupção completa do fluxo sangüíneo do vaso analisado, o que foi confirmado no presente trabalho ${ }^{40}$.

Com relação à medida de PAM, o aumento significativo da pressão arterial durante o pinçamento temporário da artéria carótida esquerda seria devido à redução do estímulo aos barorreceptores carotídeos e ao aumento da pós-carga. Em estudo realizado em humanos ${ }^{9}$ esse mesmo comportamento foi verificado, assim como, em estudos experimentais com $\operatorname{ratos}^{33,41,29}$. Esse aumento poderia incrementar o aporte sangüíneo cerebral através da circulação colateral reduzindo as alterações decorrentes da isquemia.
As alterações histológicas foram similares às observadas por Islekel e col. que foram caracterizadas por presença de neurônios encolhidos e citoplasma escuro na região CA1 de hipocampo, mas apenas nos animais que sofreram isquemia $4 \mathrm{VO}$, independentemente dos tempos de reperfusão (0, 20, 60 e 240 minutos). Os autores verificaram ainda que, na região CA3 do hipocampo não ocorreram alterações histológicas, demonstrando assim diferentes suscetibilidades das regiões cerebrais ${ }^{30}$.

No trabalho de Pulsinelli e Brierley ${ }^{29}$ em ratos Wistar com isquemia $4 \mathrm{VO}$, verificou-se nos estudos histológicos que o grau de lesão neuronal era maior nos animais que sofreram períodos mais prolongados de isquemia. Nesse estudo não apareceram microvacuolizações ${ }^{42}$, diferentemente dos nossos resultados, em que foi verificada a presença de eventuais neurônios contraídos e vacuolizados em córtex parietal e hipocampo.

\section{Conclusão}

Os modelos de isquemia e reperfusão cerebral utilizados no presente estudo não mostraram diferenças significativas entre os grupos quanto: à presença de lipoperoxidação, avaliada através da dosagem de MDA cerebral, e à avaliação histológica cerebral.

O estudo angiográfico cerebral complementar mostrou que, apesar do rigor técnico, a cauterização das artérias vertebrais pode estar sujeita a ocorrência de falhas e que mesmo com oclusão completa de todos os vasos cerebrais extracranianos, o tecido cerebral pode receber suprimento sangüíneo através de circulação colateral.

\section{Referências}

1. Moore WS. Fundamental considerations in cerebrovascular disease. In: Rutherford RB. Vascular surgery. Philadelphia: Saunders, 1995. p. 1456-73.

2. Cinelli Jr M, Sacilotto R. Isquemia cerebral de origem extracraniana. In: Maffei FHA. Doenças vasculares periféricas. Rio de Janeiro: MEDSI, 2002. p.1227-38.

3. Department of Clinical Epidemiology and Biostatistics, McMaster University, Hamilton, ON, Canada. Beneficial effect of carotid endarterectomy in symptomatic patients with high-grade carotid stenosis. North American Symptomatic Carotid
Endarterectomy Trial. N Engl J Med 1991; 25: 445-53.

4. European Carotid Trialists'Collaborative Group. European Carotid Study Trial: interim results for symptomatic patients with severe $(70-90 \%)$ or with mild $(0-29 \%)$ carotid stenosis. Lancet 1991; 337: 1235-43.

5. Asyntomatic Carotid Atherosclerosis Study Group. Study desing for randomized prospective trial of carotid endarterectomy for asyntomatic atherosclerosis. Stroke 1989; 20: 844-9.

6. Longstreth WT, Shemanski L, Lefkowitz D, O’Leary DH, Polak JF, Wolfson S. For the cardiovascular health study collaborative research group: asymptomatic internal carotid stenosis defined by ultrasound and the risk of subsequent stroke in the elderly. Stroke 1998; 29: 2371-6.

7. Young B, Moore WS, Robertson JT, Tootle JF, Ernest CB, Broderick JP, Dempsey RJ, Hesking JD. An analysis of perioperative surgical mortality and morbidity in the asymptomatic carotid atherosclerosis study. ACAS investigators: asymptomatic carotic artheriosclerosis study. Stroke 1996; 27 : 2216-24.

8. Hobson RW, Weiss DG, Fields WS Goldstone J, Moore WS, Townr JB, Wright CB. Efficacy of carotid endarterectomy for asymptomatic stenosis. N Engl J Med 1993; 328: 221-7.

9. Naylor AR, Whyman M, Wildsmith JAW, McClure JH,Jenkins A.McL, Merrick MV, Ruckley CV. Immediate effects of carotid clamp release on middle cerebral artery blood flow velocity during carotid endarterectomy. Eur J Vasc Surg 1993; 7: 308-16.

10. Sbarigia E, Speziale F, Giannoni MF, Colonna M, Panico MA, Fiorani P. Postcarotid endarterctomy hyperperfusion syndrome: preliminary observations for identifying at risk patients by transcranial doppler sonography and the acetazolamide test. Eur J Vasc Surg 1993; 7: 252-6.

11. Bralet J, Beley P, Jemaa R, Bralet AM, Beley A. Lipid metabolism, cerebral metabolic rate, and some related enzyme activities after brain infaction in rat. Stroke 1987; 18:418-25.

12. Gutteridge JMC, Haliwell B. The measurement and mechanism of lipid peroxidation in biological systems. TIBS 1990; 15: 129-35.

13. Lipton P. Ischemic cell death in brain neurons. Physiol Rev 1999; 79: p.1431-568.

14. Traystman RJ, Kirsch JR, Koehler RC. Oxygen radical mechanisms of brain injury following ischemia and reperfusion. J Appl Physiol 1991; 71: 1185-95.

15. Beckman JS, Beckman TW,Chen J, Marshall PA, Freeman BA. Apparent hydroxyl radical production by peroxynitrite: Implications for endothelial injury from nitric oxide and superoxide. Proc Natl Acad Sci USA 1990; 87: 1620-4. 
16. Watson BD. Evaluation of the concomitance of lipid peroxidation in experimental models of cerebral ischemia and stroke. Prog Brain Res 1993; 96: 69-95.

17. Kontos HA. Oxygen radicals in cerebral ischemia. The 2001 Willis Lecture. Stroke 2001; 32: 2712-6.

18. Nishizawa Y. Glutamate release and neuronal damage in ischemia. Life Sci 2001; 69: 369-81.

19. Wong GKT, Marsden PA. Nitric oxide synthases: regulation in disease. Nephrol Dial Transplant 1996; 11: 215-20.

20. Moncada, S., Palmer, R.M.J., Higgs, E.A. Nitric oxide: physiology, pathophysiology and pharmacology. Pharmacol Rev 1991; 43: 109-42.

21. Klatt P, Schmidt K, Uray G, Mayer B. Multiple catalytic functions of brain nitric oxide synthase. J Biol Chem 1993; 268 : 14781-7.

22. Davies MG, Fulton GJ, Hagen PO. Clinical biology of nitric oxide. Br J Surg 1995; 82: 1598-610.

23. Weigand MA, Laipple A, Plaschke K, Eckstein HH, Martin E, Bardenheuer HJ. Concentration changes of malondialdehyde across the cerebral vascular bed and sheedding of L-selectin during carotid endarterectomy. Stroke 1999; 30: 306-11.

24. Bacon PJ, Love A, Gupta AK, Kirkpatrick PJ, Menon DK. Plasma antioxidan Consumption associated with ischemia/ reperfusion during carotid endarterectomy. Stroke 1996; 27: 1808-11.

25. Rabl H, Khoschsorur G, Hauser H, Petek W, Esterbauer H. Diminished production of malondialdehyde after carotid artery surgery as a result of vitamin administration. Med Sci Res 1996; 24: 777-80.
26. Sato K.. Serum lipid peroxide in cerebrovascular disorders determined by a new colorimetric method. Clin Chim Acta 1978; 90: 37-43.

27. Schlesinger MJ. New radiopaque mass for vascular injection. Lab Invest 1957; 6 (1): $1-10$.

28. Ábraham H, Lazar G. Early microglial reaction following mild forebrain ischemia induced by common carotid artery occlusion in rats. Brain Res 2000; 862: 63-73.

29. Pulsinelli WA, Brierley JB. A new model of bilateral hemispheric ischemia in the unesthetised rat. Stroke 1979; 10: 267-72.

30. Islekel H, Islekel S, Güner G, Özdamar N. Evaluation of lipid peroxidation, cathelepsin $\mathrm{L}$ and acid phosphatase activities in experimental brain ischemia-reperfusion. Brain Res 1999; 843: 18-24.

31. Yoshida S, Inoh S, Asano T, So K, Kubota M, Shimazaki H, Ueta N. Effect of transient ischemia on free fatty acids and phospholipids in the gerbil brain. J Neurosurg 1980; 53: 323-31.

32. Mac Millan V. Cerebral Na+, K+ - ATPase activity during exposure to and recovery from acute ischemia. J Cereb Blood Flow Metab 1982; 2(4): 457-65.

33. Bromont C, Marie C, Bralet J. Increase lipid peroxidation in vulnerable brain regions after transient forebrain ischemia in rats. Stroke 1989; 20: 918-24.

34. Seif-el-Nasr M, Abd-El-Fattah AA. Lipid peroxide, phospholipids, glutathione levels and superoxide dismutase activity in rat brain after ischemia: effect of ginkgo biloba extract. Pharmacol Res 1995; 32: 273-8.

35. Siragusa P Tavazzi B, Lazzarino G, Pierro D, Belli A, Amorini M, Giuffrè R, Vagnozzi R. Experimental model of asymmetric brain ischemia and reperfusion in the rat. $\mathrm{J}$ Neurosurg Sci 1997; 41: 249-55.

36. Vagnozzi R, Tavazzi B, Lazzarino G, Di Pierro D, Siragusa P, Giuffré R, Giardina B. Time dependence of plasma malondialdehyde, oxipurines, and nucleosides during incomplete cerebral ischemia in the rat. Biochem Med Metab Biol 1994; 53:98-104.

37. Vagnozzi R, Lazzarino G, Tavazzi B, Di Pierrro D, Siragusa P, Giuffrè R, Giardina B. Incomplete cerebral ischemia in the rat provokes increase of tissue and plasma malondialdehyde. Biol Trace Elem Res 1995; 47: 241-6.

38. Wasovicz W, Nève J, Peretz A. Optimized steps in fluorometric determination of thiobarbituric acid-reactive substances in serum: importance of extraction $\mathrm{pH}$ and influence of sample preservation and storage. Clin Chem 1993; 39: 2522-6.

39. Bird RP, Draper HH. Comparative studies on different Methods of Malonaldehyde determination. Methods Enzimol 1984;105: 299-305.

40. Meadow W, Rudinsky B, Raju T, John E, Fornell L, Shankararao R. Correlation of flow probe determinations of common carotid artery blood flow and internal carotid artery blood flow with microsphere determinations of cerebral blood flow in piglets. Pediatr Res 1999; 45 (3):324-30.

41. Furlow Jr. TW. Cerebral ischemia produced by four-vessel occlusion in the rat: A quantitative evaluation of cerebral blood flow. Stroke 1982; 13: 852-5.

42. Pulsinelli WA, Brierley JB, Plum F. Temporal profile of neuronaldamage in a model of transient forebrain ischemia. Ann Neurol 1982; 11: 491-8

\begin{abstract}
Tardini DMS, Yoshida WB, Novelli ELB, Sequeira JL. Evaluation of two brain ischemia and reperfusion experimental models in rats with carotid temporary occlusion associated or not to vertebral occlusion. Acta Cir Bras [serial online] 2003 Nov-Dec;18(6). Available from URL: http://www.scielo.br/acb.

ABSTRACT - Purpose: To evaluate reproducibility of two experimental brain ischemia and reperfusion models. Methods: Sixty rats were randomly distributed to three experimental groups: I - (20) temporary clipping of the left carotid artery; II - (20) cauterization of vertebral arteries and temporary clipping of the left carotid artery; "Sham" - (20) simulation group, with neither ischemia nor reperfusion. All animals had permanent occlusion of right carotid artery and the three groups were subdivided into two reperfusion periods: A - 60 minutes e B - 120 minutes. Parameters verified were: mean systemic arterial blood pressure and carotid blood flow measurement; brain malondialdehyde measurement by TBARS assay and histological evaluation of the brain hemisphere submitted to ischemia and reperfusion. A supplementary brain angiography study was also conducted on 5 additional animals. Results: There was no significant difference in brain malondialdehyde dose and in frequency and severity of histological brain alterations among the three groups. In groups GI and GII, mean arterial blood pressure was significantly higher during the ischemia period. Blood flow in the periods before and after clipping increased in Groups IA and IIB, decreased in Group IB and did not alter in Group IIA. Supplementary study angiographs showed blood supply to brain through collateral circulation. Conclusion: The ischemia and reperfusion models studied did not show consistent change in brain injury markers as far as lipoperoxide production and histological damage are concerned.
\end{abstract}

KEY WORDS - Brain ischemia and reperfusion. Lipoperoxidation.

Conflito de interesse: nenhum

Correspondência: Daniela Mazza Sundefeld Tardini

Rua Venezuela, 575/121

09030-310 Santo André - SP

carlos_tardini@uol.com.br

Data do recebimento: 05/08/2003

Data da revisão: 21/08/2003

Data da aprovação: 04/09/2003 